\title{
A porta dos fundos do judiciário: o quinto constitucional e o nepotismo
}

\author{
Willian Carneiro Bianeck ${ }^{1}$
}

\begin{abstract}
RESUMO: O Poder Judiciário é composto majoritariamente por juízes de carreira. Porém, a Constituição prevê que um quinto dos membros dos Tribunais seja composto por egressos do Ministério Público e da OAB. O instituto, embora vise à oxigenação de ideias do Judiciário, em verdade acaba se tornando meio de perpetrar a prática de nepotismo, porque os critérios legais para a assunção ao cargo da magistratura pelo quinto constitucional são meramente formais, não prevendo requisitos qualitativos. Logo, os critérios reais são subjetivos e discricionários, privilegiando os candidatos que detenham heranças de capitais simbólicos. O nepotismo é um sistema político que visa à perpetuação de interesses e privilégios de classe e à manutenção das estruturas de poder, e o espaço ideal para a sua manifestação ocorre quando a lei é omissa ou obscura. Existem tentativas de dirimir a prática do nepotismo do quinto constitucional por meio de normativas e decisões judiciais, mostram-se inócuas na prática, pois não cobrem toda a complexidade das relações de parentesco e compadrio que estão enraizadas no Judiciário. Os desembargadores pelo quinto do Tribunal de Justiça do Paraná são exemplos disso.
\end{abstract}

Palavras-chave: Nepotismo. Quinto constitucional. Judiciário.

\section{The back door of the judiciary: the fifth constitutional and nepotism}

\begin{abstract}
The Judiciary Branch is composed mostly of career judges. However, the Constitution provides that a fifth of the members of the Courts will be composed of graduates of the Public Prosecutor's Office and of the OAB. The institute, although aimed at the oxygenation of ideas of the Judiciary, actually becomes a means of perpetrating the practice of nepotism, because the legal criteria for assuming the office of the magistracy by the fifth constitutional are merely formal, not providing qualitative requirements. Therefore, the real criteria are subjective and discretionary, privileging candidates who have inheritances of symbolic capital. Nepotism is a political system aimed at perpetuating class interests and privileges and maintaining structures of power, and the ideal space for its manifestation occurs when the law is omissive or obscure. There are attempts to resolve the practice of nepotism in the Fifth Constitutional by means of normative and judicial decisions, which prove to be innocuous in practice, since they do not cover all the complexity of the relations of kinship and compadrio that are rooted in the Judiciary. The judges for the fifth of the Court of Justice of Paraná are examples of this.
\end{abstract}

Keywords: Nepotism. Fifth constitutional. Judiciary.

- Enviado em 01/05/2017

- Aprovado em 17/05/2017

\footnotetext{
1 Mestrando em Sociologia pela UFPR. Uma versão preliminar desse texto foi apresentada no VIII Seminário Nacional de Sociologia e Política realizado de 17 a 19 de maio de 2017 na UFPR. E-mail: willianbianeck@gmail.com
} 


\section{INTRODUÇÃO}

O quinto constitucional é recorrentemente definido por juristas como um meio de se abrir o Poder Judiciário a ideias e posicionamentos jurídicos oriundos tanto da advocacia quanto do Ministério Público. Esse instituto é previsto no próprio texto constitucional, em seu artigo $94^{2}$. Seria, em suma, norma que oxigena democraticamente a composição do Judiciário, no sentido de se abrir àqueles que não compõem o quadro da magistratura a possibilidade de exercer a função de julgador nos Tribunais. Para a investidura no cargo de desembargador por meio do quinto constitucional, o Tribunal recebe lista sêxtupla oriunda da OAB ou do Ministério Público, e, com isso, gera lista tríplice, remetendo-a ao chefe do Poder Executivo, que nomeará o novo desembargador nos vinte dias subsequentes.

A tese que aqui se traz é no sentido contrário ao da abstração da norma jurídico. Apesar de se mostrar como instrumento interessante de tentativa de abrir o Poder Judiciário a critério de investidura à carreira judicante que não o do concurso público, na prática é possível se perceber que o quinto constitucional acaba sendo perpetuador de hegemonias políticas no Judiciário. Isso, pois, tanto a Constituição quanto as normativas que regulam a matéria sobre o quinto constitucional somente determinam requisitos meramente formais para a composição das listas. Ou seja, não há necessariamente um critério qualitativo efetivo que estabeleças as razões que levam à formação da lista tríplice do Tribunal de Justiça. ${ }^{3}$

\footnotetext{
2 Art. 94. Um quinto dos lugares dos Tribunais Regionais Federais, dos Tribunais dos Estados, e do Distrito Federal e Territórios será composto de membros, do Ministério Público, com mais de dez anos de carreira, e de advogados de notório saber jurídico e de reputação ilibada, com mais de dez anos de efetiva atividade profissional, indicados em lista sêxtupla pelos órgãos de representação das respectivas classes. Parágrafo único. Recebidas as indicações, o tribunal formará lista tríplice, enviando-a ao Poder Executivo, que, nos vinte dias subseqüentes, escolherá um de seus integrantes para nomeação. ${ }^{3}$ Veja-se, por exemplo, os critérios que a OAB criou para que escolher advogados que pertencerão à lista sêxtupla
para o cargo proveniente do quinto constitucional, constantes no Provimento no 102/2004 do CF/OAB, em seu
artigo 80: § 4o Na sessão pública de escolha dos nomes que comporão a lista, após a apresentação obrigatória do
candidato, que discorrerá sobre um dos temas tratados no parágrafo seguinte, será facultada a Comissão
designada pela Diretoria a realização da arguição prevista neste Provimento. § 5 o A arguição terá em vista aferiro
conhecimento do candidato acerca do papel do advogado como ocupante da vaga do Quinto Constitucional, do
seu compromisso com o regime democrático e a defesa e valorização da Advocacia, dos princípios gerais do Direito
e do entendimento sobre os princípios que devem nortear as relações entre advogados, juízes, membros do
Ministério Público e serventuários, bem como dos problemas inerentes ao funcionamento da Justiça. Não, há,
} 
Com isso, percebe-se que o critério real para a assunção à vaga do quinto constitucional não é a qualidade técnica do advogado ou do promotor interessados na magistratura, mas sim outros valores latentes. Esses valores são em especial os capitais sociais e políticos que o futuro desembargador detém.

O que determina, então, a investidura pelo quinto constitucional são os capitais que se acumulam pelo candidato à vaga durante a sua vida, bem como os herdados. Daí porque é recorrente se encontrar desembargadores oriundos do quinto que pertencem a famílias tradicionais ligadas ao Poder Judiciário a carreiras políticas, o que facilita e muito a ocorrência do prático do nepotismo. De acordo com OLIVEIRA:

\begin{abstract}
A teoria do nepotismo afirma a importância da família para a análise dos enredos sociais e políticos brasileiros. Procure a família, investigue as relações entre as instituições e as famílias do poder para a compreensão dos roteiros, interesses e trajetórias nas relações entre estruturas de poder e de parentesco. Muitos dos capitais sociais e códigos comportamentais sociais, explícitos ou implícitos, passam pelas lógicas de acumulação de poder familiares. A educação, as redes sociais, as alianças políticas, as culturas familiares e as histórias de vida dentro das instituições podem ser melhores compreendidas com as pesquisas das genealogias e prosopografias em questão. (OLIVEIRA, 2015, p. 334).
\end{abstract}

Um caso emblemático envolvendo o quinto constitucional que teve repercussão midiática foi o de Fábio Camargo, filho de Clayton Coutinho de Camargo, ex-Presidente do Tribunal de Justiça do Estado Paraná. Em 2012, antes de sua conturbada e controversa assunção ao cargo de Conselheiro do Tribunal de Contas do Estado do Paraná4, Fábio Camargo tentou a vaga do quinto constitucional pela OAB do Paraná; contudo, teve sua inscrição indeferida por não ter conseguido comprovar os 10 anos de prática de advocacia necessários. ${ }^{5}$ Não fosse essa falha burocrática, dificilmente Fábio Camargo não comporia os quadros da magistratura paranaense, em que a família Camargo se mostra amplamente presente desde há muito tempo (OLIVEIRA, 2015, p. 342344).

como se percebe, nenhuma exigência de um conhecimento técnico para que possa integrar a lista que será submetida ao escrutínio do Tribunal de Justiça.

4 Disponível em http://www.gazetadopovo.com.br/vida-publica/ti-anula-eleicao-de-fabio-camargo-ao-tribunal-decontas-e-manda-fazer-nova-escolha-7yl6icet0s4228n7qm8loaafs acessado em 09 de outubro de 2016.

5 Disponível em http://www.gazetadopovo.com.br/vida-publica/oab-barra-candidatura-de-fabio-camargo-ao-tj2fdvb9tsg7ef61krct7piql3i acessado em 09 de outubro de 2016. 
Assim, o presente trabalho cinge-se em estabelecer o que é o quinto constitucional além de sua ficção jurídica, quais os critérios reais que são determinantes para a escolha dos candidatos da advocacia e do Ministério Público, e como os capitais sociais e políticos são essenciais para a definição de quem integrará o corpo da magistratura do Paraná. Da mesma forma, serão analisadas as genealogias dos desembargadores que assumiram pelo quinto constitucional, demonstrando que, ao contrário de ser um meio de efetivação de ideais de democracia, o instituto serve é para a manutenção de poder das elites políticas e econômicas dentro do Poder Judiciário.

Os mecanismos e estruturas de poder que permeiam os critérios de escolha do desembargador pelo quinto constitucional mostram-se latentes, dando a falsa impressão de que há isenção política na seleção dos candidatos. Os critérios que determinam quem pode ou não assumir a vaga do Tribunal de Justiça destinada a membros da advocacia ou do Ministério são rasos e meramente burocráticos, o que acaba abrindo espaço sobremodo para que o poder político seja o fator determinante para a escolha de quem assumirá o cargo na magistratura.

As famílias das elites econômicas e políticas acabam por se manter no poder por meio do instituto, que ao invés de se efetivar como instrumento de democratização do Poder Judiciário, acaba em verdade sendo meio de perpetuação do poder dessas famílias. A genealogia dos desembargadores que assumiram pelo quinto constitucional demonstra que a grande maioria advém de famílias tradicionais política e economicamente. O estudo dessa genealogia é necessário para melhor compreensão de como os capitais políticos e sociais são os fatores determinantes para a determinação dos motivos verdadeiros que estabelecem quem deve pertencer ou não à magistratura por meio do quinto constitucional.

Por meio da externalização das redes de influência e como os capitais sociais e políticos influem na determinação de quem irá assumir o cargo de desembargador no Tribunal de Justiça, pretende-se demonstrar os reais motivos que levam à determinação de quem e por que se consegue a assunção do cargo judicante. Da mesma forma, será demonstrado como o pertencimento a famílias tradicionais acaba sendo o fator determinante para a escolha do desembargador pelo quinto, de modo que o instituto do quinto constitucional se torna forma de concretização da prática do nepotismo. A prática do nepotismo está imbricada nas mais várias 
esferas do poder público, sendo que pode ser dito como um sistema político propriamente dito, não como fenômenos isolados.

\begin{abstract}
O nepotismo é um sistema político. O nepotismo é uma rede social e política e política de interesses. O nepotismo é uma estratégia de classes, de grupos sociais, e de famílias para a obtenção e preservação do poder político e da dominação da elite. O nepotismo teve as suas origens no parentesco e favoritismo dos papas com seus parentes e passou para o poder civil. A prática muitas vezes corrupta de nomeação de parentes nas velhas esferas eclesiásticas cunhou o léxico na tradição política. (OLIVEIRA, 2012, p. 14).
\end{abstract}

É a partir dessa ideia de rede política de interesses que se analisará como o quinto constitucional camufla a realidade perversa do nepotismo, pois os mecanismos que definem quem vai ou não ter o "direito" ${ }^{6}$ a uma função judicante no Estado não são aqueles atrelados às abstrações normativas do direito, mas sim são os que essas complexas redes de favores políticos e sociais conduzem. Pode-se afirmar inclusive que o quinto constitucional não tem qualquer tipo de restrição constitucional ou legal no que tange à possibilidade de nomeação de parentes de qualquer grau ao cargo de desembargador?

A genealogia preza pela história familiar do indivíduo, fornecendo todo um arcabouço de conhecimentos sobre as relações de parentesco e políticas, e como influem na estrutura social (OLIVEIRA, 2012, p. 77). O estudo da genealogia dos desembargadores oriundos do quinto

\footnotetext{
${ }^{6} \mathrm{~A}$ ideia de transformação de privilégios em direitos configura uma das mais nefastas irradiações do nepotismo nas relações sociais e políticas, pois camufla todas as redes de influências que causam as diferenças naturalizadas na sociedades. "O que assegura, portanto, a 'justiça' e a legitimidade do privilégio moderno é o fato de que ele seja percebido como conquista e esforço individual. Nesse sentido, podemos falar que a ideologia principal do mundo moderno é a 'meritocracia', ou seja, a ilusão, ainda que seja uma ilusão bem fundamentada na propaganda e na indústria cultural, de que os privilégios modernos são 'justos'. Sua justiça reide no fato de que 'é do interesse de todos' que existam 'recompensas' para indivíduos de alto desempenho em funções importantes para a reprodução da sociedade. O 'privilégio' individual é legitimado na sociedade moderna e democrática, fundamentada na pressuposição de igualdade e liberdade dos indivíduos, apenas e enquanto exista essa pressuposição". (SOUZA, 2016, p. 51)

${ }^{7}$ Há dois casos que saltam aos olhos pela falta de pudor com que dois Ministros do Supremo Tribunal Federal usaram e abusaram de suas redes de influências para que suas filhas assumissem os cargos de desembargadoras, o que demonstra sequer haver questionamento quanto à legitimidade de tais métodos para a concretização do quinto constitucional: são os casos de Mariana Fux, filha do Ministro Luiz Fux, e de Letícia Mello, filha do Ministro Marco Aurélio de Mello (<http://www1.folha.uol.com.br/poder/2014/03/1427835-filha-de-ministro-do-stf-enomeada-ao-trf-apos-derrotar-nomes-experientes.shtml>). Aliás, o próprio Ministro Marco Aurélio de Mello é fruto dessa rede de nepotismo: somente foi nomeado para o Supremo porque é primo do ex-Presidente da República Fernando Collor de Mello, durante o período em que presidia o Brasil.
} 
constitucional não pode preterir também que a própria Ordem dos Advogados e o próprio Ministério Público têm as suas famílias oligárquicas. Embora não seja a ênfase da pesquisa proposta, negar essa realidade é presumir que haja isenções nas duas instituições que nunca se fizeram presentes. ${ }^{8}$

Assim, as redes de nepotismo estão diluídas nas nomeações dos desembargadores pelo quinto constitucional, e o instituto que deveria ter a finalidade de democratização do Poder Judiciário, torna-se carta branca para a perpetuação do poder de famílias que se encontram inseridas no protagonismo do Judiciário desde tempos mais remotos no Brasil. E o Tribunal de Justiça do Paraná é laboratório de pesquisa sociológica perfeito para a pesquisa, pois não foge à regra.

DOIS CASOS ORIUNDOS DA ADVOCACIA: OCTÁVIO FISCHER E ROSANA AMARA GIRARDI FACHIN

Octávio Campos Fischer foi empossado como desembargador no Tribunal de Justiça do Estado do Paraná para a vaga do quinto constitucional destinada à advocacia em 25 junho de 2013. A sua biografia é lacônica nos sites da $O A B / P R^{9}$ e do Tribunal de Justiça do Estado do Paraná ${ }^{10}$. Contudo, Octávio Fischer é filho de Felix Fischer, Ministro do Superior Tribunal de

\footnotetext{
${ }^{8}$ A própria $O A B$ reconheceu há pouco tempo como as relações de parentesco influenciavam diretamente no resultado para a eleição do quinto constitucional, motivo pelo qual tem criado mecanismos que visam à contenção das redes de nepotismo da instituição. (http://www.oab.org.br/noticia/27422/oab-proibe-nepotismoem-lista-do-quinto-constitucional). Acessado em 09 de outubro de 2016.
}

9 "O advogado Octavio Campos Fischer foi escolhido nesta terça-feira (25) pelo governador Beto Richa, para ocupar o cargo de desembargador do Tribunal de Justiça do Paraná (TJ-PR), pelo quinto constitucional da advocacia. A lista tríplice, oriunda da lista sêxtupla votada pelo Conselho Pleno da OAB Paraná e definida durante sessão do Pleno do TJ na última segunda-feira (24), era também composta pelos advogados Munir Abbage e Ramon de Medeiros Nogueira. Na sessão do Conselho Pleno, que definiu os nomes da lista sêxtupla, o advogado Octavio Fischer foi o mais votado entre os seis nomes. Octavio Campos Fischer é professor de Direito Tributário da graduação e pós-graduação das Faculdades Integradas do Brasil (Unibrasil). Foi conselheiro estadual da OAB Paraná (2010-2012) e membro de diversas comissões da Seccional. É doutor em Direito Tributário pela Universidade Federal do Paraná (2002), com vasta produção científica nesta área." Disponível em http://www.oabpr.com.br/Noticias.aspx?id=17570 acessado em 09 de outubro de 2016.

10 “Octávio Campos Fischer, nasceu no dia 13 de julho de 1971. Formou-se pela Faculdade de Direito da Universidade Federal do Paraná (UFPR) em 1993. É doutor em Direito Constitucional Tributário e Mestre em 
Justiça, antigo membro dos quadros do Ministério Público do Estado do Paraná ${ }^{11}$. Tal fato, embora oculto propositadamente de sua biografia, não pode ser olvidado de sua trajetória até a sua posse como desembargador.

Octávio não é o único Fischer nos quadros do Tribunal de Justiça do Paraná. Seu irmão, Fernando Bardelli Silva Fischer, também pertence ao quadro da magistratura paranaense como juiz de direito de primeiro grau.

Antes de se tornar desembargador pelo quinto constitucional, Octávio Fischer atuava como advogado, inclusive nas Cortes Superiores em Brasília. Por possuir capitais simbólicos herdados, tendo em vista a sua tradição familiar, tinha facilidade de acesso a Ministros e a políticos em Brasília. Há suspeitas de que Fischer intermediava a venda de decisões com o Ministro aposentado compulsoriamente Paulo Medina12.

Rosana Amara Girardi Fachin foi nomeada para o cargo de desembargadora do Tribunal de Justiça do Paraná em 21 de outubro de 1999. Conforme sua biografia no site do Tribunal de Justiça do Paraná:

Direito Tributário, ambos pela Faculdade de Direito da Universidade Federal do Paraná. Atuou como advogado nas áreas de Direito Tributário, Cível e Empresarial em Curitiba. Foi Conselheiro Estadual da OAB/PR - de2007 a 2009 (suplente) e de 2010 a 2012 (titular). Como professor atuou com as disciplinas de Direito Tributário no Programa de Mestrado em Direito e Graduação em Direito nas Faculdades Integradas do Brasil-Unibrasil e no Programa de Mestrado em Direito do Instituto Brasiliense de Direito Público (IDP/DF); também como professor da Escola da Magistratura do Paraná e da Escola Superior de Advocacia do Brasil, Seccional do Paraná. Tem os seguintes livros publicados: "A Contribuição ao PIS", "Efeitos da declaração de inconstitucionalidade no Direito Tributário", Tributos e Direitos Fundamentais", "PIS- Cofins: Questões Polêmicas e Atuais"(coordenador em conjunto), "Reforma do Judiciário: Primeiras Reflexões sobre a Emenda Constitucional no. 45/2004 (em conjunto), "Anais do XV Congresso Brasiliense de Direito Constitucional do IDP ( em conjunto), além de mais de 40 artigos publicados. Em 25 de junho de 2013 foi nomeado ao cargo de desembargador, em vaga destinada à OAB/PR, pelo Quinto Constitucional.". Disponível em www.tjpr.jus.br acessado em 09 de outubro de 2016.

11“Felix Fischer (Hamburgo, 30 de agosto de 1947) é um juiz naturalizado brasileiro, de origem alemã. É ministro do Superior Tribunal de Justiça (STJ) desde 1996, nomeado pelo presidente Fernando Henrique Cardoso após indicação por seus pares no Ministério Público e seleção em lista tríplice pelos ministros do STJ. Foi presidente dessa corte no período de 2012 a 2014.". Disponível em https://pt.wikipedia.org/wiki/Felix Fischer . A acessado em 09 de outubro de 2016. Um curiosidade: por ser de alemão nato e ter perfil "mão pesada" com as causas criminais, Fischer tem um apelido "carinhoso" e preconceituoso nos bastidores da advocacia criminal: Felix Führer.

12 Disponível em http://www.jornali9.com/noticias/denuncia/ministro-que-favoreceu-camara-tem-filho-acusadopor-trafico-influencia-no-stj. Acessado em 09 de outubro de 2016. 
Rosana Amara Girardi Fachin, filha de Fortunato Girardi e Anna Felomena Treis Girardi, nasceu no dia 16 de agosto de 1957, em Guaramirim (SC). Bacharela em Direito pela Universidade Federal do Paraná, turma 1981.

Após formada, exerceu a advocacia na capital e é membro da "International Society of Family Law" (Holanda) e do Instituto Brasileiro de Direito de Família (BH).

Em 21 de outubro de 1999, através da vaga do quinto constitucional destinada à OAB, foi nomeada juíza do Tribunal de Alçada e, no dia 31 de dezembro de 2004, foi promovida a desembargadora do Tribunal de Justiça do Paraná.

Especialista em Direito Processual pela Pontifícia Universidade Católica do Paraná e IBEJ. Mestra em Direito das Relações Sociais pela Universidade Positivo, onde se especializou em Filosofia do Direito e Pensamento Crítico.

O que há de oculto na biografia de Rosana Amara Girardi Fachin: Rosana é casada com Luiz Edson Fachin, Ministro do Supremo Tribunal Federal. Embora tenha assumido o cargo antes de seu marido ser nomeado Ministro, Luiz Edson Fachin detinha amplo capital político e social à época: era procurador do Estado do Paraná e Professor Titular de Direito Civil da Universidade Federal do Paraná. A filha do casal, Melina Girardi Fachin, herdou a carreira acadêmica do pai: também é professora na Universidade Federal do Paraná. ${ }^{13}$

\section{DOIS CASOS ORIUNDOS DO MINISTÉRIO PÚBLICO: ÂNGELA KHURY MUNHOZ DA ROCHA}

Ângela Khury Munhoz da Rocha tomou posse da vaga de quinto constitucional destinada a membros do Ministério Público em 28 de julho de 2009. Sua biografia no site do Tribunal de Justiça do Estado do Paraná também omite o fato de ser sobrinha de Aníbal Khury e prima de Alexandre Khury ${ }^{14}$; contudo, Ângela Khury não esconde tais fatos em entrevistas. Inclusive afirma que pelo fato de ter toda essa tradição familiar, tem mais ônus do que bônus, ou seja, mais é

13 DIsponível em http://buscatextual.cnpq.br/buscatextual/visualizacv.do?id=K4746686H6. Acessado em 09 de outubro de 2016.

14 Ângela Khury Munhoz da Rocha, filha de Nilton Khury e Arlette Therezinha Khury, nasceu no dia 26 de outubro de 1963, em Curitiba (PR). Bacharel em Direito pela Universidade Federal do Paraná, turma 1986. Ingressou no Ministério Público paranaense em 1987, como substituta da comarca de São José dos Pinhais. Como promotora de justiça, exerceu o cargo nas comarcas de Mallet, União da Vitória, Rebouças, Laranjeiras do Sul e Curitiba, onde atuou na Promotoria Especial de Defesa do Consumidor. Em 28 de julho de 2009, através da vaga do quinto constitucional destinada ao Ministério Público, foi nomeada desembargadora do Tribunal de Justiça do Paraná. Disponível em www.tjpr.jus.br acessado em 09 de outubro de 2016. 
atrapalhada do que ajudada ${ }^{15}$; na mesma entrevista, porém, afirma que trabalhou como chefe de gabinete de Milton Riquelme de Macedo, procurador de justiça que atuou de modo a favorecer o ex-governador Roberto Requião em $2007^{16}$, que foi o governador que nomeou Ângela ao cargo de desembargadora pela quinto, num caso de escutas telefônicas clandestinas feitas por um policial dentro da Casa Civil.

Aníbal Khury, seu tio, foi pessoa de destaque no cenário político paranaense, e criou 88 cidades no Estado ${ }^{17}$. Seu nome é dado a infindáveis escolas, ruas, parques e prédios. Aníbal deixou muitos cartórios a seus descendentes no Paraná, o que garante poder político e econômico a seus herdeiros.

Já Alexandre Maranhão Khury, primo de Ângela e neto de Aníbal Khury, também seguiu bem a carreira política, aproveitando toda a herança de capitais de sua família. Casou-se com Paula Mussi Khury, que é neta de Paulo Pimentel, político e ex-dono do Grupo Paulo Pimentel, filiada ao SBT. Alexandre começou cedo sua carreira política: aos 21 anos foi eleito vereador em Curitiba, no ano de 2000; atualmente ocupa o cargo de deputado estadual. Alexandre Khury é suspeito de cometer irregularidades em licitações na Assembleia Legislativa do Estado do Paraná18.

Outro dado relevante que a desembargadora Ângela Khury Munhoz da Rocha não dá tanto destaque em sua trajetória é o fato de ser casada com o médico Luiz Eduardo Munhoz da Rocha, que Ihe deu a parte final de seu sobrenome. Luiz Eduardo é neto de Bento Munhoz da Rocha, ex-

\footnotetext{
${ }^{15}$ http://www.gazetadopovo.com.br/vida-publica/tenho-mais-onus-do-que-bonus-sendo-parente-de-politicobr1n9bx1s3kwwgd0i0x92qhxq. Acessado em 09 de outubro de 2016. Destaca-se esse excerto: “Aos 45 anos de idade, mulher do médico Luiz Eduardo Munhoz da Rocha e com uma filha de 10 anos, a nova desembargadora teve ascensão rápida. Um ano depois de se formar em Direito pela Universidade Federal do Paraná, em 1986, já entrava para o Ministério Público como promotora de justiça substituta em São José dos Pinhais. Passou por comarcas no interior e desde 1990 está em Curitiba. O pai, Nipton Khury, já falecido, era irmão do ex-presidente da Assembleia Legislativa Anibal Khury, que morreu há 9 anos. Apesar do sobrenome influente, ela diz que o parentesco não teve influência na sua carreira profissional.".
}

16 Disponível em http://www.gazetadopovo.com.br/vida-publica/pps-pede-para-que-cnmp-investigue-miltonriquelme-de-macedo-ag6pnt8eq1bmpho5aqatvqc7i acessado em 09 de outubro de 2016.

17 Disponível em http://www.gazetadopovo.com.br/vida-publica/anibal-khury-criou-88-cidades-do-estadoapie09fa9ds4bnpmx51806c7i acessado em 09 de outubro de 2016.

18 Disponível em http://g1.globo.com/pr/parana/noticia/2015/03/mp-denuncia-alexandre-curi-por-improbidade-emlicitacoes-da-alep.html acessado em 09 de outubro de 2016. 
governador do Estado do Paraná, o que aumenta ainda mais as redes de influências da desembargadora Ângela.

Já Clayton Coutinho de Camargo não esconde em momento algum a influência que seu sobrenome tem sobre a sua carreira. Eis a íntegra de sua biografia extraída do site Tribunal de Justiça do Estado do Paraná:

\begin{abstract}
Clayton Coutinho de Camargo, filho do desembargador Heliantho Guimarães Camargo e Maria José Coutinho Camargo, nasceu no dia 5 de março de 1946, em Curitiba (PR). Bacharel pela Faculdade de Direito de Curitiba, turma 1973.
\end{abstract}

Em 1974, após concurso, ingressou no Ministério Público como promotor substituto na comarca de Foz do Iguaçu. Exerceu, também, suas funções nas comarcas de Campo Largo, Palmeira e Paranaguá. Efetivado na carreira em 1976, atuou nas comarcas de Mandaguari, Bocaiúva do Sul, Colombo, Assis Chateaubriand, Ponta Grossa e Curitiba.

Em 20 de abril de 1995, através da vaga do quinto constitucional destinada ao Ministério Público. Nomeado juiz do Tribunal de Alçada, assumiu a presidência conlcuindo o mandato do Dr. Antônio Domingos Ramina que assumiu o cargo de desembargador do Tribunal de Justiça e após eleição, assumiu a presidência para a biênio 2002/03. Em sua gestão foi responsável pela instalação do Tribunal de Alçada em sede própria, criação de câmaras especializadas e elevou o número de juízes de 50 para 75 magistrados. Articulou politicamente a fusão dos tribunais de Alçada e de Justiça. No dia 12 de setembro de 2003, foi promovido ao cargo de desembargador do Tribunal de Justiça do Paraná.

Foi Coordenador Geral da Promotoria de Justiça de Defesa do Consumidor (1988) e procurador de Justiça (1990), integrou o Conselho Superior do Ministério Público, no biênio 1991/92.

Eleito presidente do Tribunal de Justiça do Paraná, assumiu no dia 10 de fevereiro de 2013, para o biênio 2013/2014.

Renunciou ao cargo no dia 24 de setembro de 2013, por motivo de saúde.

Embora o motivo oficial da renúncia de Clayton Coutinho de Camargo tenha sido motivo de saúde, é notório que o desembargador sofria acusações de corrupção e tráfico de influências quando do exercício de seu mandato ${ }^{19}$, tanto que chegou a ser cassado do cargo de desembargador. Contudo, o Conselho Nacional de Justiça cassou a decisão ${ }^{20}$. E, como já constatado na introdução do presente estudo, o legado de sua família no poder público continua com o seu filho Fábio Camargo.

\footnotetext{
19 Disponível em http://veja.abril.com.br/brasil/envolvido-em-denuncia-de-venda-de-sentencas-presidente-do-tj-doparana-renuncia/acessado em 09 de outubro de 2016. ${ }^{20}$ Disponível em http://www.conjur.com.br/2015-jun-30/depois-600-dias-cnj-cassa-afastamento-desembargador-tj-pr
acessado em 09 de outubro de 2016.
} 


\section{CONSIDERAÇÕES FINAIS}

As redes de influências que os candidatos ao cargo de desembargador embora não sejam fatores oficiais para a nomeação à vaga do quinto constitucional, mostram-se circunstâncias relevantes que condicionam a escolha da pessoa que assumirá a função judicante. Por mais que os candidatos à vaga tentem omitir tais traços de capitais simbólicos em suas declarações e biografias pessoais ou até mesmo minimizar as influências e inclusive valorá-los negativamente, não há como se olvidar o fato de que quem herda esses capitais tem maiores chances de integrar os quadros da magistratura.

E um dos fatores que contribuem para que esse sistema político de nepotismo continue a funcionar sem pejo é a ausência de mecanismos idôneos de fiscalização e controle de nepotismo no quinto constitucional. Enquanto isso não ocorre, os estudos das trajetórias políticas, das biografias, das genealogias, das prosopografias mostram-se necessários para escancarar os fatores reais que levam a pessoa a assumir a vaga pelo quinto constitucional.

\section{REFERÊNCIAS}

ALMEIDA, Frederico Normanha Ribeiro de. A nobreza togada: As elites jurídicas e a política da justiça no Brasil. Tese (Doutorado em Ciência Política) - Departamento de Ciência Política da Universidade de São Paulo, São Paulo, 2010.

COENEN-HUTHER, Jacques. Sociologia das elites. Lisboa: Piaget, 2004.

MONGELOS, Silvia Avelina Arias Mongelos. O recrutamento de advogados pelo quinto constitucional para o Tribunal de Justiça do Paraná: um estudo dos processos seletivos de 2010 e 2012. Dissertação (Mestrado) - Departamento de Ciência Política da Universidade Federal do Paraná, Curitiba, 2013.

OLIVEIRA, Ricardo. Estado, classe dominante e parentesco no Paraná. Blumenau: Nova Letra, 2015. 
. Na teia do nepotismo. Curitiba: Insight, 2012.

O silêncio dos vencedores: genealogia, classe dominante e estado no Paraná. Curitiba: Moinho do Verbo, 2001.

PALADINO, Andrea. Os desembargadores do Tribunal de Justiça do Paraná: uma análise do perfil social e orientação jurídica nas carreiras de magistrado e do quinto constitucional. Dissertação (Mestrado) - Departamento de Ciência Política da Universidade Federal do Paraná, Curitiba, 2013.

SOUZA. Jessé. A ralé brasileira: quem é e como vive. Belo Horizonte: UFMG, 2016. 